Description. Elongate oval, tapering toward the base. Slightly bulging on the side away from the hair in one specimen, or in the others narrower and more symmetrical. About two and a half times as long as wide. The empty shell hyaline and beautifully sculptured with hexagonal reticulations. The hexagons somewhat variable in size and perfectness in different

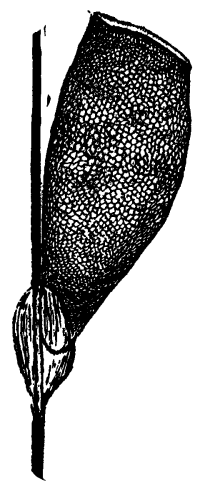

parts of the shell, but average ones about onetwentieth of the width of the shell. The surface apparently smooth, the angles of the reticulations not beset with points as in the eggs of the Short-nosed ox-louse. Attached to the hair by a cement mass about one-third the length of the egg, as shown in the figure. The cement mass varies in shape, the distance it extends along the hair and the remoteness of the attachment from the root of the hair. The sloping base of the egg is included more or less in the cement mass, and the egg stands somewhat obliquely outward from the hair.

Below we give measurements of the three eggs observed. The figure, drawn to scale by the writer, shows the egg enlarged 40 times.

Measurements: Specimen (a), length, .863 $\mathrm{mm}$; width, $.38 \mathrm{~mm}$; width of operculum, $.265 \mathrm{~mm}$.; from base of hair, $5 \mathrm{~mm}$.; cement mass, $.345 \mathrm{~mm}$.; hexagonal reticulations of shell, .02 $\mathrm{mm}$.

Specimen (b), length, $.805 \mathrm{~mm}$; width, $.379 \mathrm{~mm}$.; width of operculum, .253 mm.; from base of hair, $5.75 \mathrm{~mm}$.; cement mass, $.288 \mathrm{~mm}$.

Specimen (c), length, $.805 \mathrm{~mm}$; width, $.379 \mathrm{~mm}$.; width of operculum, .265 mm.; from base of hair, Io $\mathrm{mm}$. ; cement mass, $.312 \mathrm{~mm}$.

\title{
ON THE VALIDITY OF THE TACHINID GENUS CELATORIA.
}

BY D. W. COQUILLETT, WASHINGTON, D. C.

On page 235 of the second volume of Insect life, the writer erected the genus Celatoria for the reception of an interesting Californian species of Tachina fly that preys upon the adults of the destructive Diabrotica soror, as many as one-third of these beetles sometimes falling a prey to the attacks of this parasite. The validity of this genus has been called in question by the well- known authors, Messrs. Brauer and Bergenstamm, who cite it as a synonym of the previously described genus Besseria (Die zweiflugler des Kaiserlichen Museums zu Wien, vi, 154 and I89; also p. 220, where the species, crawiii Coq., is erroneously credited to C. H. T. Townsend). That these two genera are very distinct from each other may easily be seen by the following 
comparisons, the characters of Besseria being taken from the figures and descriptions given by the authors above mentioned. For the sake of uniformity, it will be assumed that the sex having

\section{Besseria.}

Front of male destitute of orbital bristles.

Face perpendicular, in profile strongly concave; epistoma projecting.

Facial ridges bare.

Third joint of antennae less than twice as long as the second.

Genitalia of female nearly as broad as the abdomen, incapable of being concealed within the latter.

From this it will be seen that not only are these two genera not identical, but their differences are so great that it becomes a matter of much surprise that the authors above mentioned, who have the process on the second ventral segment is the female, to which sex the above authors assign it, although in the genus Celatoria this form undoubtedly represents the male :-

\section{Celatoria.}

Front of male bearing two pairs of orbital bristles.

Face retreating, in profile strongly convex; epistoma retreating.

Facial ridges bristly to or beyond the middle.

Third joint of antennae at least four times as long as the second.

Genitalia horny, not broader than the tibia, capable of concealment in a groove on the venter.

not hesitated to establish new genera on very trivial characters, should have arrived at the conclusion that these two forms are one and the same.

\section{THE LARVA OF BUTALIS BASILARIS ZELL.: THE RELATIONS OF ITS SETAE.}

\section{BY HARRISON G. DYAR, NEW YORK CITY.}

In Butalis basilaris Zeller (determined by Prof. C. H. Fernald) we have a Tineid larva which lives an exposed life. Its superficial resemblance to a Pterophorid is extremely close and it lives in the same situations. The larvae were found eating into the young leaves and buds at the ends of the growing shoots of the blackberry in June and again in August, at Keene Valley, N. Y.

Larva. Cylindrical, the abdominal feet slender, the circular planta with a ring of six crochets regularly distributed. No secondary hairs; setae long; with flattened or winged-furcate ends, arising from cylindrical produced tubercles; $\mathrm{i}$ and ii approximate, their bases fused; iii lateral, iv and $\mathrm{v}$ united, vi subventral posteriorly, vii of three setae on the anterior side of the base of the foot; viii very small, next mid-ventral line. Color of the body shining green, closely adapted to the color of the young leaves; setae and tubercles white, adding a mossy appearance to the larva and causing it to still further resemble the leaves. Head slightly testaceous; width $.6 \mathrm{~mm}$., length of larva $5 \mathrm{~mm}$.

When mature the larva spins a cocoon of a coarse open network of silk at the ground 

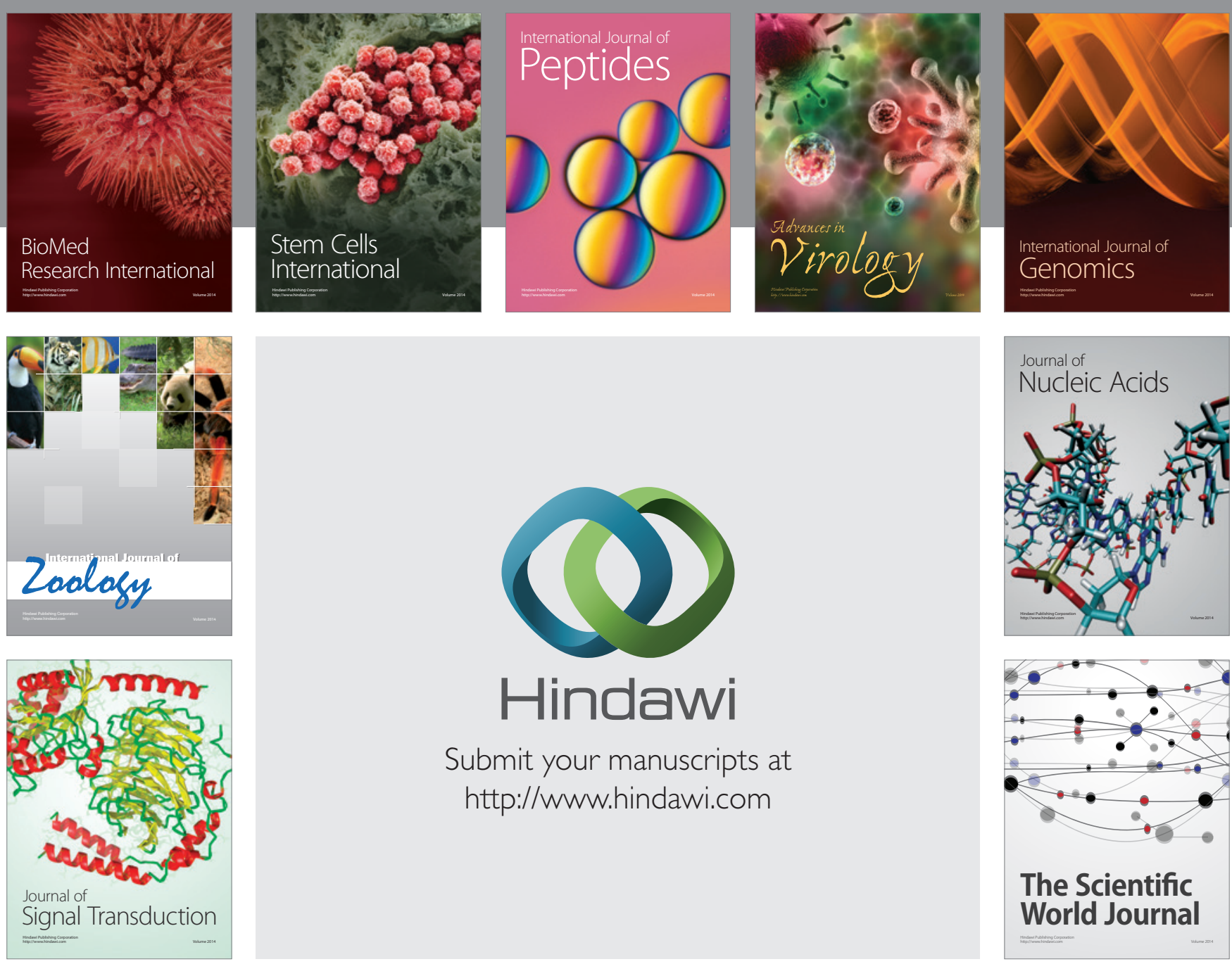

Submit your manuscripts at

http://www.hindawi.com
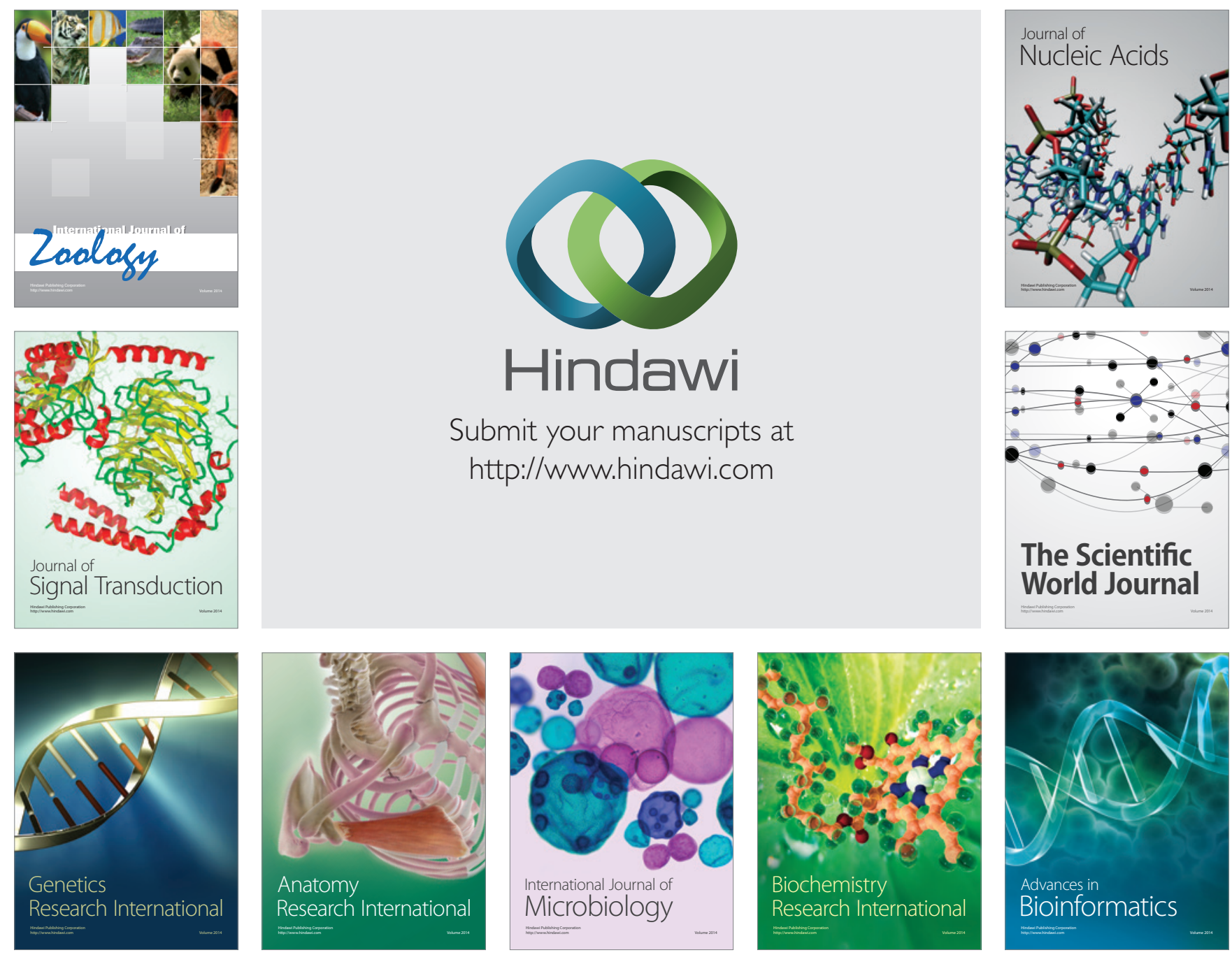

The Scientific World Journal
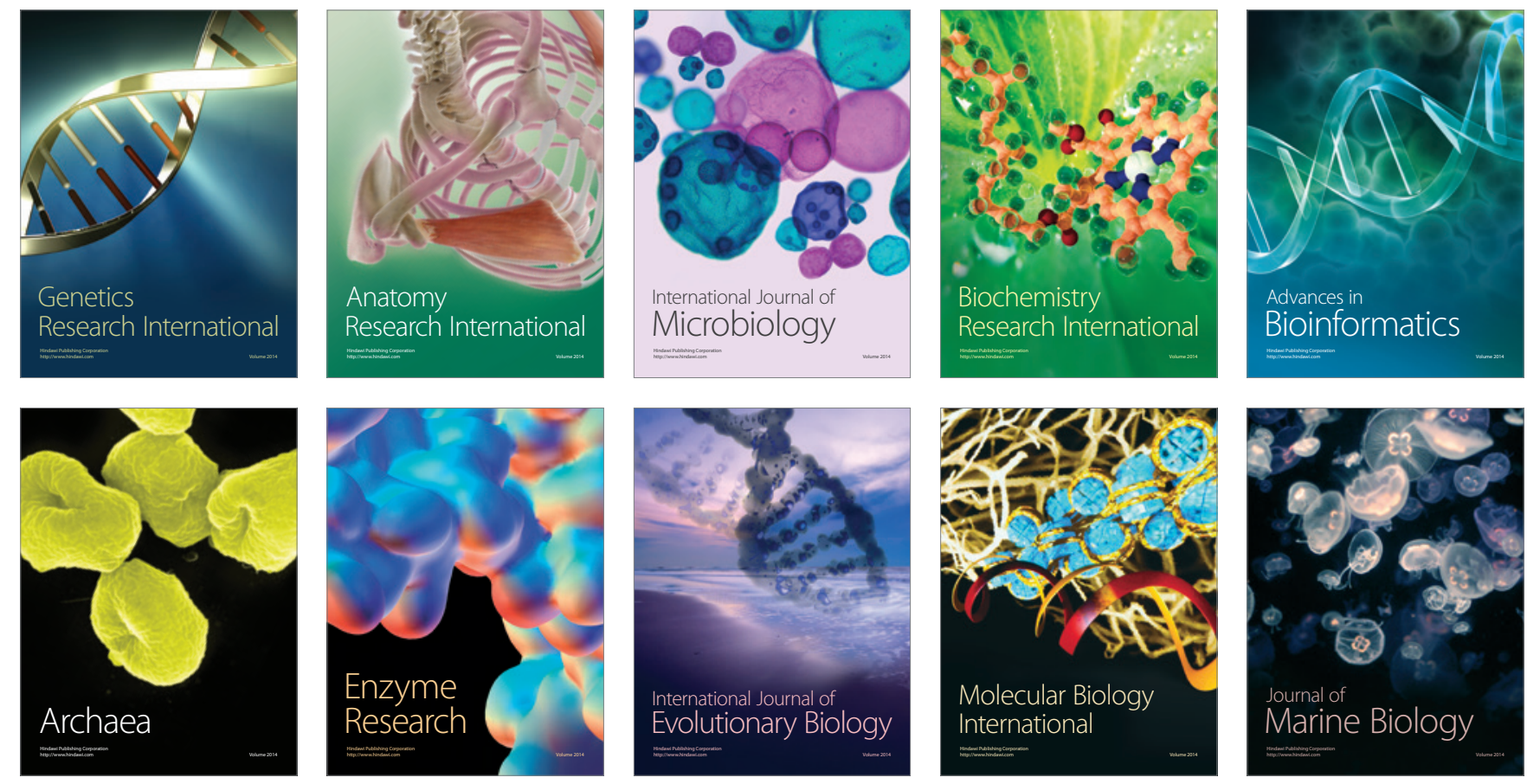